\title{
Kemampuan Representasi Matematis Anak Berkebutuhan Khusus Tipe Celebral Palsy dalam Menyelesaikan Soal Matematika di Sekolah Inklusi
}

\author{
Ahmad Farid Haebah ${ }^{1}$, Subanji², Cholis Sa'dijah ${ }^{2}$ \\ ${ }^{1}$ Pendidikan Dasar-Universitas Negeri Malang \\ ${ }^{2}$ Pendidikan Matematika-Universitas Negeri Malang
}

\begin{tabular}{l}
\hline \hline INFO ARTIKEL \\
\hline Riwayat Artikel: \\
Diterima: 29-01-2019 \\
Disetujui: 17-03-2019 \\
\hline
\end{tabular}

\section{Kata kunci:}

mathematical representation, celebral palsy; inclusive school; representasi matematis, celebral palsy; sekolah inklusi

Alamat Korespondensi:
Ahmad Farid Haebah
Pendidikan Dasar
Universitas Negeri Malang
Jalan Semarang 5 Malang
E-mail: haebahfaridahmad@ gmail.com

\section{ABSTRAK}

Abstract: This study aims to analyze and describe the mathematical representation of children with special needs of the type of celebral in solving math problems in inclusive schools. This study uses a case study method with a qualitative approach. The research subjects were children with special needs of the type of celebral palsy who were members of the inclusive school, namely the sixth grade students of Muhammad Hatta Islamic Elementary School in Malang. The results showed that children with special needs of the ty pe of celebral palsy were able to do representations well.

\begin{abstract}
Abstrak: Penelitian ini bertujuan untuk menganalisis dan mendeskripsikan representasi matematis anak berkebutuhan khusus tipe celebral palsy dalam menyelesaikan soal matematika di sekolah inklusi. Penelitian ini menggunakan metode studi kasus dengan pendekatan kualitatif. Subjek penelitian adalah anak berkebutuhan khusus type celebral palsy y ang tergabung dalam sekolah inklusi, yaitu siswa kelas VI SD Islam Muhammad Hatta kota Malang. Hasil penelitian menunjukkan bahwa anak berkebutuhan khusus tipe celebral palsy telah mampu melakukan representasi dengan baik.
\end{abstract}

Setiap anak di dunia, tak terkecuali Anak Berkebutuhan Khusus (ABK) merupakan karunia dan amanah dari Tuhan Yang Maha Esa yang dalam diri setiap ABK melekat harkat dan martabat sebagai manusia seutuhnya. ABK tak ada bedanya deng an kita sebagai manusia di hadapan Tuhan. ABK justru perlu kita rangkul, meskipun memiliki kekurangan karena kondisi fisiknya berbeda dengan anak normal lainnya. Adapun yang membedakan hanyalah karena anak ABK cacat fisik, cacat mental, maupun cacat sosial. Dalam segala aspek kehidupan, ABK hendaknya mempunyai hak yang sama dengan anak-anak yang lain pada umumnya. Begitu pula dalam hal pendidikan, sebagai seorang pendidik kita harus menyadari bahwa ABK juga mempunyai hak untuk mendapatkan pendidikan yang layak yaitu mendapatkan pengajaran dan pendidikan agar membentuk kepribadian yang terdidik, mandiri, dan terampil, termasuk ABK tipe celebralpalsy.

Celebral Palsy diklasifikasikan menurut derajat perkembangan otak. Celebral Palsy juga diklasifikasikan menurut derajat kecatatannya, yaitu ringan, sedang, dan berat. Ciri umum dari anak Celebral Palsy adalah sebagian besar dari mereka memiliki kekakuan jari dan tangan sehingga mengalami kesulitan dalam menggenggam, di dalam anggota gerak tubuhnya terdapat ketidaksempurnaan atau sebagian dari tubuhnya tidak seimbang (lebih kecil/lebih besar) dari biasanya, mengalami kesulitan dalam menggerakkan anggota tubuhnya, dan anggota gerak layu, kaku, lemah/lumpuh (Jenks, De Moor, \& Van Lieshout, 2009).

Salah satu bentuk kepedulian pemerintah dalam mewujudkan agar anak ABK memperoleh pendidikan yang layak adalah dengan dibentuknya pendidikan inklusi. Pendidikan inklusi merupakan sebuah pendidikan regular yang didalamnya terdapat anak berkebutuhan khusus. Adanya pendidikan inklusi ini ABK diajar serta dididik bersama anak-anak lainnya (normal) untuk dapat meningkatkan potensi yang ia miliki (Danner \& Fowler, 2015). Dalam pendidikan inklusi ini semua pihak yang tergabung di dalamnya termasuk guru pendamping harus memiliki kecakapan dalam memberikan pelayanan terbaik kepada sis wa baik di ruang lingkup sekolah maupun di luar sekolah (Deku \& Vanderpuye, 2017). Karena semakin meningkatnya jumlah murid dengan gangguan spektrum autisme (Autism spectrum disorder) maka sepatutnya pemerintah memperbanyak sekolah inklusi untuk mengurangi diskriminasi terhadap anak ABK (Emam, 2014).

Sesuai dengan konferensi dunia "education for all", dimana pendidikan itu milik semua orang tidak terkecuali ABK, sehingga ABK dapat menempuh pendidikan di sekolah umum bersama anak-anak (normal) lainnya dengan kurikulum yang telah disesuaikan (Gunarhadi, 2005). Adanya pendidikan inklusi akan mengurangi kemungkinan terjadinya diskriminasi terhadap ABK, 
dan ABK dapat menempuh pendidikan serta belajar beradaptasi di lingkungan masyarakat yang sebenarnya yaitu masyarakat umum yang bias disebut disable and able person (Gross, 2017). Menurut Pant, Pankaj, Joshi, (2016) bahwa anak ABK yang di sekolahkan di sekolah inklusi memiliki perkembangan yang signifikan dalam hal kognitifnya, walaupun tidak secara keseluruhan termasuk perkembangannya dalam pembelajaran matematika.

Seperti pada umumnya, pendidikan inklusi memiliki kurikulum yang sama dengan sekolah umum lainnya, termasuk pembelajaran matematika dan sudah menjadi rahasia umum bahwa pelajaran matematika merupakan momok bagi siswa dan sebagian besar siswa tidak menyukainya. Ketidaksenangan siswa pada matematika terjadi pula pada ABK yang tentunya akan memengaruhi presetasi belajar mereka serta kreativitas mereka dalam belajar matematika. Beberapa faktor yang memengaruhi keberhasilan siswa tidak datang dari siswa itu sendiri, tetapi dipengaruhi juga oleh kompetensi guru matematika, kemampuan siswa, dan strategi yang digunakan oleh guru dalam pembelajaran khususnya di kelas inklusi termasuk dalam mere presentasi matematika tersebut. Aljabar termasuk materi pembelajaran yang sulit untuk anak merepresentasikannya (Smedt, Swillen, Verschaffel, \& Ghesqui, 2009).

Demi terwujudnya harapan tentang berhasil tidaknya siswa, maka semua anak perlu dibekali kemampuan matematis yang baik agar semua anak nantinya mampu dengan baik mengaplikasikan kemampuannya ke dalam disiplin ilmu lainnya. Salah satunya adalah kemampuan representasi (Rahmad, Ipung, Abdur, Sisworo, \& Dwi, 2016). Untuk mewujudkannya, guru dan lembaga kependidikan memiliki peran penting dan menjadi barisan terdepan dalam proses pengemban gan dan peninngkatan kemampuan matematis sis wa sebagai peserta didik, termasuk anak ABK.

Memecahkan masalah termasuk kemampuan memahami masalah matematika, merancang model matematika dan bagaimana penyelesaiannya serta mengomunikasikan gagasan melalui simbol, diagram, media, atau tabel merupakan salah satu tujuan pembelajaran matematika yang tertuang dalam Permendiknas No. 22 Tahun 2006 tanggal 23 Mei 2006 (Depdiknas, 2006). Dari uraian di atas terlihat bahwa kemampuan matematika memiliki peranan penting dan harus dimiliki oleh setiap anak termasuk anak ABK. Selain kemampuan memecahkan masalah matematika, kemampuan representasi matematis juga menjadi slah satu kemampuan yang harus dimiliki oleh setiap siswa. Hal tersebut juga diperkuat oleh National Council ofTeachers of Mathematics yang menetapkan lima standarproses kemampuan matematis, yaitu kemampuan pemecahan masalah, penalaran dan pembuktian, berkomunikasi, koneksi, dan representasi. Berdasarkan uraian di atas, semakin terlihat bahwa kemampuan representasi matematika memiliki peranan penting untuk memudahkan anak dalam memahami matematika dengan baik, seperti yang dikemukakan Minarni \& Napitupulu, (2017) bahwa saat ini banyak guru dan peneliti menemukan siswa yang miskin akan cara merepresentasikan matematika. Oleh karena itu, perlunya memberikan penguatan kepada siswa akan pentingnya representasi pada pembelajaran matematika.

Setiap siswa akan selalu berbeda dalam merepresentasikan dengan siswa lainnya. Beberapa kategori dalam merepresentasikan dan menjadi kesulitan bagi siswa adalah kesulitan dalam memahami gambar, menggambar diagram, membaca grafik dengan benar, memahami matematika yang konseptual (Surya, Sabandar, Kusumah, \& Darhim, 2013). Menurut Debrenti, (2015) dalam penelitiannya mengemukakan bahwa siswa sulit dalam representasi visualnya dan menurut (Solovieva, Rosas Rivera, Quintanar, \& García, 2013) pada penelitiannya menemukan sulitnya siswa dalam merepresentasi simbolis pada pembelajaran matematika. Kaitannya dengan anak ABK seorang peneliti asal Mexico (Jitendra, Nelson, Pulles, Kiss, \& Houseworth, 2016) mengemukakan bahwa penguatan representasi tidak hanya diperuntukkan kepada siswa normal saja, tetapi juga kepada anak ABK.

Mengenai pentingnya representasi dalam pembelajaran matematika, beberapa peneliti telah membuktikan bahwa representasi matematika adalah sebuah standar proses yang tidak boleh hilang dalam diri setiap siswa termasuk siswa ABK (Kalathil \& Sherin, 2000), dalam studinya menyampaikan bahwa representasi memiliki tiga fungsi representasi, yaitu (1) menggunakan representasi sebagai media informasi kepada guru tentang bagaimana siswa berpikir mengenai suatu konteks atau ide matematika, (2) menggunakan representasiuntuk memyampaikan informasi tentang pola dan kecend erungan diantara siswa, (3) guru dan siswa menggunakan representasi sebagai alat bantu dalam proses pembelajaran. Dari latar belakang tersebut, penulis mengambil judul "Representasi Matematis Anak Berkebutuhan Khusus tipe Celebral Palsy dalammenyelesaikan soal matematika di sekolah inklusi". Dimana penulis menuliskan bagaimana siswa ABK dalam merepresentasikan matematika dengan bahasa mereka.

\section{METODE}

Pada penelitian ini menggunakan metode penelitian studikasus dengan pendekatan kualitatif. Lokasi penelitian berada di SD Islam Muhammad Hatta kota Malang dengan satu orang siswa berkebutuhan Khusus yang tergabung dalam kelas regular yaitu kelas V SD. Sekolah ini dijadikan sebagai lokasi penelitian dikarenakan merupakan sekolah yang menjadi proyek untuk menerapkan sekolah yang berbasis inklusi. Instrumen yang digunakan pada penelitian ini berupa instrumen tes, observasi, dan wawancara. Data akan diperoleh melalui tes yang diberikan kepada subjek dan diperkuat dengan wawancara yang dilakukan peneliti terhadap subjek. Proses analisis data ini dimulai dengan mengumpulkan data dari hasil observasi, wawancara, dan dokumentasi. Selanjutnya, data tersebut diolah sehingga menghasilkan suatu kesimpulan. Adapun indikator representasi yang digunakan pada penelitian ini sebagaimana ditunjukkan pada tabel 1. 
Tabel 1. Indikator Representasi

\begin{tabular}{|c|c|c|}
\hline No & Jenis Representasi & Indikator \\
\hline 1 & Grafik & 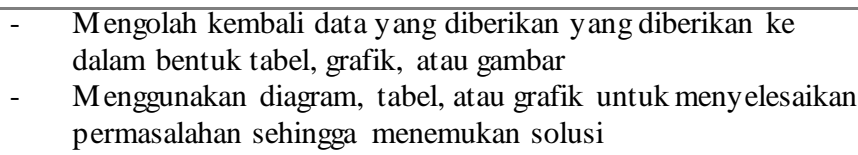 \\
\hline 2 & Verbal & $\begin{array}{ll}\text { - } & \text { Membuat cerita dan kesimpulan dengan representasi y ang ada } \\
\text { - } & \text { Menggunakan kata-kata dalam meny elesaikan soal }\end{array}$ \\
\hline
\end{tabular}

HASIL

Celebral Palsy diklasifikasikan menurut derajat perkembangan otak. Celebral Palsy juga diklasifikasikan menurut derajat kecatatannya, yaitu ringan, sedang, dan berat. Ciri umum dari anak Celebral Palsy adalah mengalami kesulitan dalam menggenggam karena jari dan tangan kaku, pada bagian anggota gerak memiliki ketidakseimbangan (lebih besar/lebih kecil) dari biasanya, kesulitan dalam gerakan, dan anggota gerak layu, kaku, lemah/lumpuh (Portel, 2007).

Ciri-ciri tersebut persis yang dialami oleh YK, dimana sebagian anggota geraknya tidak berfungsi. Kondisi ini lantas tidak membuat YK tidak mampu merepresentasikan matematika dengan baik, tetapi dari hasil tes representasi matematis pada soal pecahan YK mampu merepresentasikan bentuk pecahan ke dalam bentuk gambar.

Hal ini didukung oleh hasil wawancara yang menunjukkan bahwa YK tergabung di kelas inklusi sejak kelas I mampu memberikan alasan yang jelas mengenai jawaban-jawaban yang telah dia kerjakan. Berikut adalah hasil tes dari siswa YK yang menunjukkan bahwa sis wa yang memiliki keterbatasan sudah mampu merepresentasikan bentuk pecahan ke dalam bentukgambar (Tabel 2).

Tabel 2. Hasil Tes Siswa YK

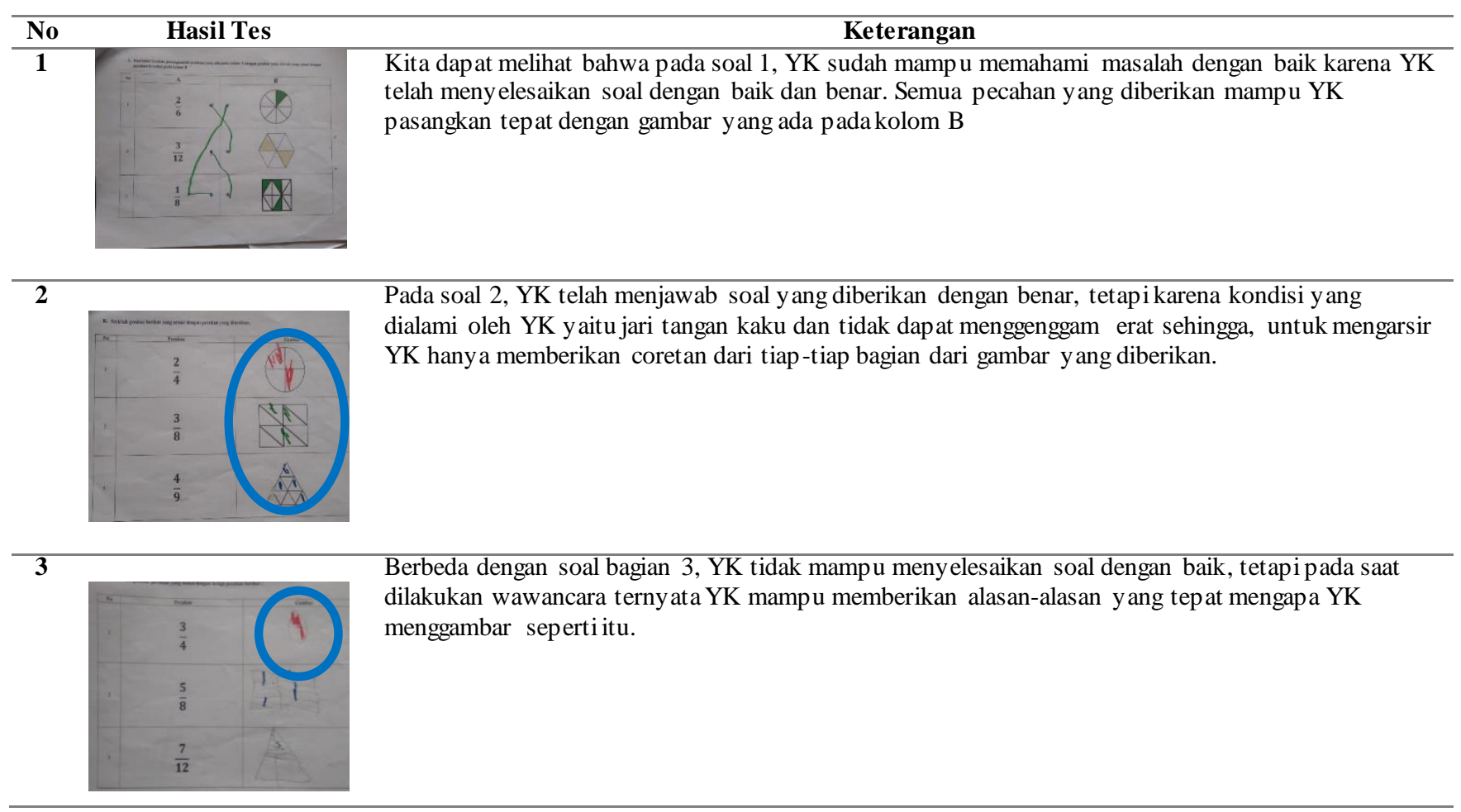

Sesuaidengan indikator representasimatematis tipe visualbahwa YK telah mampu membuat representasike representasi gambar untukmemperjelas masalah dan memfasilitasi penyelesaiannya. Dengan kondisi YK sebagai anak berkebutuhan khusus yang tergabung dalam kelas inklusi, YK mampu menyesuaikan dirinya dengan anak normal lainnya. YK dapat mengikuti pelajaran dengan baik, sama seperti anak lainnya.

Dengan adanya program pemerintah untuk memberikan kesempatan kepada anak ABK untuk tergabung di sekolah regular, akan memberikan kesempatan untuk setiap anak lebih meningkatkan kreativitas dan pembelajaran matematika akan diterima secara merata, seperti anak-anak lain pada umumnya. 


\section{PEMBAHASAN}

Representasi didefinisikan sebagai konfigurasi karakter, gambar, dan benda konkret yang dapat mewakili sesu atu yang lain. Dalam pembelajaran matematika dasar, representasimemainkan peran yang sangat penting, termasuk pada materi pecahan (Gagatsis, 2004). Representasi menjadi sesuatu halyang sangat penting dalam pembelajaran matematika karena digunakan sis wa untuk menginterpretasi dan menerjemahkan hasil pemikiran mereka. Akan tetapi, pada kenyataannya representasiyang dimiliki oleh setiap anak berbeda satu dengan lainnya. Perbedaan ini dialami juga oleh anak berkebutuhan khusus yang tergabung di sekolah inklusi. Perbedaan tersebut dapat dilihat pada hasil tes yang dikerjakan oleh anak berkebutuhan khusus (celebral palsy) sebagai subjek penelitian ini.

Dalam proses pengerjaannya, soal dibagi ke dalam tiga karakteristik masalah representasi, yaitu representasi korespondensi, representasi semi-konstruksi, dan representasikonstruksi. Representasi korespondensi adalah sebuah representasi matematis dimana siswa diharapkan mampu memasangkan sebuah pecahan yang ada pada kolom A dengan gambar yang diarsir yang sesuai dengan yang ada pada kolom B. Representasi semi-konstruksi adalah sebuah representasi dimana anak diharapkan mampu untuk mengarsir gambar dari sebuah pecahan yang diberikan, sedangkan representasikonstruksiadalah anak diharapkan mampu menggambar pecahan yang mewakili pecahan yang diberikan.

Pada proses representasi korespondensi subjek telah mampu melakukan representasi dengan baik. Pada proses semikonstruksi, ABK dengan tipe celebral palsy yang memiliki jari tangan kaku dan tidak dapat menggenggam ini ternyata telah mampu melakukan representasidengan baik. Walaupun hasil yang diberikan kurang maksimal, tetapi maksud dari anak dengan tipe celebral palsy ini sudah benar. Seperti ditujukkan pada gambar 1, anak ini mencoba mengarsir sesuai dengan pecahan yang diberikan, tetapi karena kondisinya yang tidak memungkinkan sehingga hanya memberikan coretan dari setiap bagian pecahan yang dimaksud.

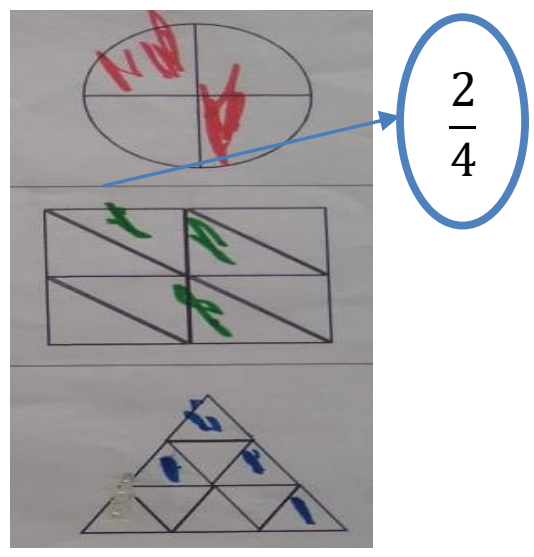

\section{Gambar 1. Cara ABK Tipe Celebral Palsy Dalam Mengarsir Pecahan}

\section{SIMPULAN}

Dapat disimpulkan bahwa anak berkebutuhan khusus yang tergabung dalamkelas inklusi mampu melakukan representasi matematis dengan baik. Ditandai dengan proses pengerjaan soal yang terbagi ke dalam tiga karakteristik masalah representasi, yaitu representasi korespondensi (memasangkan), representasi semi-konstruksi (mengarsir), dan representasi kontruksi (menggambar). Anak dengan tipe celebral palsy, misalnya walaupun anggota gerak tubuhnya tidak berfungsi dengan baik, akan tetapi pemahamannya tentang matematika sangat baik, dan representasi matematisnya juga sudah benar, didukung oleh hasil wawancara yang dilakukan peneliti terhadap anak dengan tipe celebral palsy ini. Adapun saran yang dapat peneliti sampaikan kepada masyarakat agar perlunya ramah disabilitas, dan kepada pemerintah agar mencanangkan perlunya setiap sekolah menyelenggarakan sekolah inklusi.

\section{DAFTAR RUJUKAN}

Danner, N., \& Fowler, S. A. (2015). Montessori and Non-MontessoriEarly Childhood Teachers' Attitudes toward Inclusion and Access. Journal of Montessori Research, 1(1), 28-41.

Debrenti, E. (2015). Visual Representations in Mathematics Teaching: An Experiment with Students.Acta Didactica Napocensia, 8(1), 1-15.

Deku, P., \& Vanderpuye, I. (2017). Perspectives of Teachers Regarding Inclusive Education in Ghana. International Journal of Whole Schooling, 13(3), 39-54.

Emam, M. M. (2014). The Closeness of Fit: Towards an Ecomap for the Inclusion of Pupils with ASD in Mainstream Schools. International Education Studies, 7(3), 112-125. https://doi.org/10.5539/ies.v7n3p112 
Gross, B. J. (2017). Strategies for Transitioning to an Inclusive School Environment Support Strategies for School Staff to use with Families Common Questions Families have Regarding Inclusive Environments, (June), 1-3.

Gunarhadi. (2005). Penanganan Anak Sindroma Down dalam Lingkungan Keluarga dan Sekolah. Jakarta: Departemen Pendidikan Nasional.

Jenks, K. M., De Moor, J., \& Van Lieshout, E. C. D. M. (2009). Arithmetic Difficulties in Children with Cerebral Palsy are Related to Executive Function and Working Memory. Journal of Child Psychologyand Psychiatry and Allied Disciplines, 50(7), 824-833. https://doi.org/10.1111/j.1469-7610.2008.02031.x

Jitendra, A. K., Nelson, G., Pulles, S. M., Kiss, A. J., \& Houseworth, J. (2016). Is Mathematical Representation of Problems an Evidence-based Strategy for Students with Mathematics Difficulties? Exceptional Children, 83(1), 8-25. https://doi.org/10.1177/0014402915625062

Kalathil, R. R., \& Sherin, M. G. (2000). Role of Students' Representations in the Mathematics Classroom. Fourth International Conference of the Learning Science, 27-28.

Minarni, A., \& Napitupulu, E. E. (2017). Developing Instruction Materials Based on Joyful PBL to Improve Students Mathematical Representation Ability. International Education Studies, 10(9), 23. https://doi.org/10.5539/ies.v10n9p23

Pant, Pankaj., Joshi, P. K. (2016). A Comparative Study of Emotional Stability of Visually Impaired Students Studying at Secondary Level in Inclusive Setup and Special Schools. Journal of Education and Practice, 7(22), 53-58.

Rahmad, B. A., Ipung, Y., Abdur, R. A., Sisworo., \& Dwi, R. (2016). Mathematical Representation by Students in Building Relational Understanding on Concepts of Area and Perimeter of Rectangle. Educational Research and Reviews, 11(21), 2002-2008. https://doi.org/10.5897/ERR2016.2813

Smedt, B. De, Swillen, A., Verschaffel, L., \& Ghesqui, P. (2009). Mathematical Learning Disabilities, 10(November 2008), 410. https://doi.org/10.1002/ddrr.44

Solovieva, Y., Rosas Rivera, Y., Quintanar, L., \& García, M. A. (2013). Symbolic Representation for Introduction of Concept of Decimal System in Mexican School Children. International Education Studies, 6(10), 102-111. https://doi.org/10.5539/ies.v6n10p102

Surya, E., Sabandar, J., Kusumah, Y. S., \& Darhim. (2013). Mathematical Problem Solving by CTL. IndoMS, 4(1), $113-126$. 